\title{
NOTAS HISTORICAS
}

\section{CONTRIBUIÇÃO PARA A HISTÓRIA DO DESENVOLVIMENTO DA PSICANALISE EM SAO PAULO}

\author{
VIRGINIA LEONE, BICUDO *
}

A participação de São Paulo na vida cultural do país tem sido sempre das tnais valiosas e fecundas. Um dos setores em que sua contribuição se torna digna de destaque é o da psicanálise. Achamos oportuno apresentar resumidamente os passos seguicos, em São Paulo, pelos que concorreram para colocar a psicanálise no presente estado. Para tal relato, valemo-nos da documentação de Durval Marcondes, que, se não foi o pioneiro em tôda a extensão da palavra, o foi no que se refere à aplicação terapêutica da psicanálise. $O$ movimento psicanalítico em São Paulo pode ser dividido em três etapas: divulgação da teoria; aplicação terapêutica do método; formação sistematizada de psicanalistas.

Por volta de 1919, o Prof. Franco da Rocha já se referia à psicanálise em suas aulas de psiquiatria na Faculdade de Medicina de São Paulo. Dada a sua posiçâo como professor catedrático, podemos perceber 0 alcance de sua atividade, divulgando a teoria psicanalítica entre aquêles que se destinavam à complexa tarefa de curar. "O Estado de São Paulo" de 20-3-1919, publicou a preleção de abertura do Curso de Clínica Psiquiátrica em 1919 - "Do Delírio em Geral" na qual Franco da Rocha se fundamentou nos conhecimentos psicanalíticos. Em 1920, Franco da Rocha publicou o livro "A doutrina de Freud", de cujo Irefácio extraímos o seguinte: "Antes dêste livro, já havia eu escrito diversas preleções sôbre a doutrina de Freud, sòmente para meus alunos da Faculdade ce Medicina de São Paulo. Pareceu-me, porém, que muitos leitores encontravan dificuldades em compreender tôda a doutrina exposta no resumo das preleçõe;, justamente por ser mui conciso. A razão mais forte, porém, é outra: é a falta de hábito de estudos psicológicos e, talvez também, a falta de observação direta dos pacientes neuro e psicopatas". Em uma citação de Bleuler, o autor apresenta explicaçōes dos ataques apaixonados que se desencadearam contra a psicanálise: “Era preciso não ser psicólogo para deixar de os compreender (os críticos furiosos). A doutrina de Freud vai de encontro a alguma coisa mais do que ao simples misoneismo; ela agita e resolve não sòmente dogmas científicos profundámente encrustados na alma, como também sentimentos que nos são caros e sagrados, que se acham em tão íntima ligação com a compreensão atual da Moral, que não é possível a muita gente pensar uma coisa sem pensar na outra. $E$, portanto, sob a influência de sentimentos, aliás louváveis, que os psicanalistas são considerados por êles como fantasias sem critério, pelo lado intelectual, e como estragadores da moralidade, pelo lado ético".

A resistência que a psicanálise desperta é um fenômeno natural que pode ser cientificamente compreendido. Uma pesquisa de fácil execução, sugerida por Durval Marcondes, consistiria em um inquérito entre pessoas de diferentes gerações, através do qual se procurasse definir a atitude dos inqueridos para com a psica-

- Assistente de Psicanálise na Escola Livre de Sociologia e Política da Univ. S. Paulo. 
nálise. Supomos que a aceitação da teoria psicanalítica iria tornando-se maior na razão inversa da ordenação das respostas segundo a idade: quanto mais jovem a pessoa inquirida, menor resistência psíquica. A hipótese que propomos implica numa relação entre resistència psíquica e evolução cultural. $O$ que houve de notável em Franco da Rocha foi seu espírito aberto à teoria, em um período no qual era tão apoucada, entre nós, a literatura sôbre o assunto. Franco da Rocha destacou-se por sua inteligência liberta em alto grau dos entraves das inibiçôes emocionais que, freqüentemente, se expressam na mentalidade refratária ao que é novo. Dotado de excepcional personalidade, pôde enfrentar a resistência cla época, bem como antever a situação da psicanálise num futuro próximo, quando, em carta, escreveu a Durval Marcondes: "Há de chegar um dia em que a psicanálise será coisa assentada e sabida, aceita por todo o mundo. Os próprios detratores dirão: não fui nunca contrário a ela; sempre a aceitei; era lá um ou outro tópico que provocava dúvida, mas sempre admirei Freud e sua doutrina, etc., etc.".

A freqüência com que vimos citando Durval Marcondes já deixou claro que é quem segue, cronològicamente falando, como pessoa que teve papel destacado no desenvolvimento da psicanálise em São Paulo. Estudioso da psicanálise, apresentou em 1926 seu primeiro trabalho na defêsa de tese sôbre a aplicação da psicanálise ao estudo da estética literária, no concurso à cadeira de Literatura do Ginásio do Estado. Referindo-se a esta monografia, Freud dirigiu-lhe, em carta, palavras de estímulo, dizendo-lhe que prosseguisse naquêles estudos, cujos frutos seriam amplamente compensadores. Mas foi por volta de 1927 que Durval Marcondes começou a empregar a técnica psicanalítica no tratamento de neuróticos, inaugurando em São Paulo a aplicação terapêutica do método de Freud.

Com a finaldiade de promover o estudo e a divulgação da psicanálise, por iniciativa de Durval Marcondes, fundou-se em 1927, em São Paulo, a Sociedade Brasileira de Psicanálise, tendo por presidente Franco da Rocha. Entre outros, fizeram parte da Sociedade: Raul Briquet, Lourenço Filho, Wladimir Kehl, A. Almeida Junior, Osório Cesar, Tomé Alvarenga, James Ferraz Alvim e Paulo Almeida Toledo.

Já em 1929, por meio de comunicações sôbre a utilização clínica da psicanálise e seus resultados, pela focalização, em vários trabalhos, do problema dos fa:ôres psíquicos nas doenças orgânicas, definindo o ponto de vista psicológico na medicina, Durval Marcondes procurava infiltrar na medicina em geral os conhecimentos psicanalíticos tão valiosos para o médico. Em entrevista por êle concedida à "Folha da Noite" de 19-8-1929, encontramos definida a orientação que hoje se concretiza na medicina psicossomática: "Não é só para o especialista em moléstias nervosas que os conhecimentos psicanalíticos têm valor, sendo de grande utilidade mesmo para a clínica geral, onde a terapêutica está intimamente relacionada com a situação afetiva do doente. A influência pessoal do médico, tão decisiva em certos casos, apoia-se em disposiçōes afetivas do paciente, que o clínico consciencioso não pode desconhecer. Por outro lado, é preciso considerar que os sintomas corporais são, muitas vezes, determinados ou, pelo menos, agravados por fatôres de ordem psíquica inaccessiveis ao tratamento medicamentoso e que os meios psicoterápicos vulgares nem sempre permitem combater".

O curso de várias conferências sôbre psicanálise ministrado por Durval Marcondes em 1930, sob os auspícios da Sociedade de Educação, com Raul Briquet na presidéncia, constituiu acontecimento cultural de grande relêvo. A assistência que afluiu ao anfiteatro do Jardim da Infância, onde o curso se realizou, evi- 
denciava que o público já estava dominado pelo interêsse por idéias até pouco tāo chocantes e esdrúxulas.

Vencidas as primeiras etapas, fazia-se sentir cada vez com maior pressão a necessidade do ensino e da formação de técnicos. Em 1934, Durval Marcondes recebe uma carta de A. A. Brill, que era nessa época o presidente da Associação Psicanalitica Americana, pedindo-lhe para conseguir, nos meios universitários de São Paulo, acolhimento a psicanalistas liberais e antinazistas, que se achavam pràticamente sem lar. Apesar de todos os esforços, não foi possível conseguir o apôio oficial pedido. Assim, perdemos a oportunidade única de receber cooperação cultural de cientistas que hoje ocupam posição de liderança no campo da psicanálise. Evidentemente, não havíamos alcançado maturação para ter interêsse na acolhida de tão ilustres exilados.

Continuando no intento de desenvolver o ensino, Durval Marcondes dá, ein 1935, entrevistas à imprensa, como a publicada em “A Gazeta” de 5-2-1935 sob - título "São Paulo precisa ter um Instituto de Psicanálise". Anteriormente, havia encetado negociações com Max Eitingon, então presidente da Associação Psicanalítica Internacional, para a vinda de um psicanalista com o fim de formar um centro de estudo em São Paulo. Já a esta altura interessavam-se pela psicanálise Darci Mendonça Uchoa e Flávio Rodrigues Dias.

Finalmente, em 1937, aparece no consultório de Durval Marcondes a Dra. Adelaide Koch, formada pelo Instituto de Psicanálise de Berlim. Vindo ao seu encontro por informação de Ernest Jones, a dra. Koch possibilitava a realização dos planos de desenvolvimento da psicanálise em São Paulo. Uma vez bem estabelecida a necessidade do especialista ter sido psicanalisado, foram iniciadas, no mesmo ano, as psicanálises didáticas dos candidatos a essa especialização. Durante os primeiros anos, Adelaide Koch trabalhou só, fazendo as psicanálises didáticas, o ensino teórico e o controle das psicanálises conduzidas pelos estudantes já suficientemente adiantados na própria análise e no conhecimento da teoria. An lado destas atividades, também desenvolveu trabalho de divulgação por meio de conferências, entrevistas para a imprensa e participação em congressos. Publicou, entre nós, os trabalhos: "Neurose dos pais - Neurose dos filhos", "Considerações Psicanalíticas sôbre Símbolos e Contos Populares", "Elementos Básicos da Terapia Psicanalítica".

De alguns anos para cá, a formação de técnicos conta com a colaboração do psicanalista Frank Philips, tendo Durval Marcondes também contribuído no ensino da teoria.

Em 1939, foi criada a cadeira de psicanálise na Escola Livre de Sociologia e Política, instituição complementar da Universidade de São Paulo, inaugurando-se, ássim, o ensino sistemático da psicanálise em escola superior do país. É professor da referida cadeira, desde o início, o Dr. Durval Marcondes, tendo, a princípio, como professor assistente, a Dra. Adelaide Koch e, de 1941 a esta parte, a psicanalista Virginia Leone Bicudo. Esse curso não visa, naturalmente, a formacão de psicanalistas, tendo como finalidade, apenas, oferecer aos estudantes os conhecimentos psicanalíticos necessários à boa compreensão dos fenômenos sociais.

Fundou-se, em 1944, a Sociedade Psicanalítica de São Paulo, que se filion ¿े Associação Internacional de Psicanálise, tendo "The International Journal of Psycho-Analysis" (vol. XXVII, 1946) publicado um relatório sôbre as atividades da Sociedade Psicanalítica de São Paulo até aquela data. Além das atividades didáticas e terapêuticas, os membros da Sociedade Psicanalítica de São Paulo têm desenvolvido seminários para estudos de problemas referentes à teoria e ao mé- 
todo psicanalítico. Participaram os psicanalistas, em 1946, do seminário de psicologia social da Faculdade de Filosofia da Universidade de São Paulo, cabendo a Frank Philips o desenvolvimento de um capítulo sôbre psicanálise num livro de psicologia que está na fase final de execução.

Em julho de 1945, a Sociedade recebeu a visita do psicanalista argentino Arnaldo Rascowski, aproximação de sentido cultural valiosa para a discussão de problemas comuns aos grupos de psicanalistas. No fim do mesmo ano tivemos tambem oportunidade de conhecer pessoalmente Angel Garma, que em sua viagem de regresso dos Estados Unidos para a Argentina, deu-nos a honra de sua visita.

Apesar das naturais dificuldades, o progresso da psicanálise em São Paulo tem sido proveitoso. Possa nosso esfôrço ser motivo de simpatia e servir de estímulo a novas iniciativas no sentido de um maior desenvolvimento da psicanálise entre nós.

Rua Guararás 90 - casa 1 - S. Paulo 